\title{
An empirical study on the impact of stress on the relationship between locus of control and job satisfaction and job performance
}

\author{
Mahboobeh Khorshidifar $^{\mathrm{a}^{*}}$ and Ali Abedi ${ }^{\mathrm{a}}$
}

${ }^{a}$ Department of Industrial Engineering, Iran University of Science \& Technology (Digital Unit), Tehran, Iran

\begin{tabular}{l}
\hline A R T I C L E I N F O \\
\hline Article history: \\
Received April 3, 2011 \\
Received in Revised form \\
May, 24, 2011 \\
Accepted 26 May 2011 \\
Available online \\
11 June 2011 \\
\hline Keywords: \\
Job satisfaction \\
Locus of control \\
Accounting \\
Performance measurement \\
Stress components
\end{tabular}

\section{A B S T R A C T}

\begin{abstract}
Stress plays an important role on job satisfaction in many industries such as accounting. We present an empirical study to examine the impact of job stress on the relationship between the locus of control and accountants' job satisfaction. The study selects a sample of 65 senior and regular accountants who work for thirteen different regional municipalities of city of Mashad located in east part of Iran. The study uses different well-known questionnaire methods such as stress diagnostic survey, locus of control, job satisfaction and employees' performance to perform the study. The results indicate that the stress is on average level for the dominant locos of control factors and job satisfaction and employee performance are in relatively high level. The study also reveals that there are four important factors of role of ambiguity, quantitative overload, career development and handling other workers' responsibilities play important role on job satisfaction and managing career development has important impact on the performance of accountants.
\end{abstract}

(c) 2011 Growing Science Ltd. All rights reserved.

\section{Introduction}

Stress has different negative impacts on people's physiological and behavior, which could reduce job performance and satisfaction, significantly. There are different studies that suggest introspection and extroversion, locus of control (LOC) and personality type A and B play vital impact on exacerbating or moderating job stress. The level of stress increases among accountants since they not only have to be accountable against their managers but also they are also under pressure on behalf of organizations they work. Accountants normally need to do their duties in relax work environment and it is necessary to determine the important factors on increasing stress in their work environment. There are different studies, which suggest five important factors on job stress: role ambiguity, role conflict, quantitative overload, career progress and accepting other people's responsibility. The first one, role ambiguity, happens when accountants are not aware of job expectations. Role conflict appears when there are different conflicting requests from an accountant. Stress in job is mostly created when there are no job promotion opportunities in job carriers. Stress is a kind of experience that may have either beneficial or damaging consequences and it is a physical response. However, the stressors are

* Corresponding author. Tel. +98

E-mail addresses: mahboobeh.khorshidifar@yahoo.com (M. Khorshidifar) 
typically social, psychological, or symbolic, and require no physical action. A continuous flow stress can result a major strain on a person's body that can lead to illness and eventually it can cause fatigue, disease, disability, aging, and death (Matteson \& Ivancevich, 1987).

Lo and Ramayah (2011) presented a method for mentoring and job satisfaction in Malaysian small and medium enterprises (SMEs). In their study, they gathered the necessary data required to examine the relationship between mentoring and employees' job satisfaction among employees from small and medium enterprises in Malaysia. In their survey, they distributed 200 questionnaires to executives of the middle and lower management level from the 21 selected SMEs. Their results indicated that there was a positive relationship between career mentoring and all dimensions in job satisfaction such as co-workers, job itself, promotion and supervisors. However, they reported no significant relationship between psychosocial mentoring and three aspects of employees' job satisfaction, namely coworkers, job itself, and promotion.

In this study, we present an empirical survey to study the impact of stress on accounting jobs. There are several questions associated with this survey. The main question examines whether people with external LOC have more stress with people with internal LOC. In order to find an appropriate response to this question we setup other questions based on five main parameters of role ambiguity, role conflict, quantitative overload, career progress and accepting other people's responsibility. The first questions examines whether people with internal locos of control are more satisfied with their job compared with people with external locos of control. Patten (2005) studied the impact of LOC on internal auditor job performance and satisfaction. He reported that those internal auditors with more internal LOC tendencies seem to outperform cohorts with more external traits. Contrary to expectations, reported job satisfaction levels for internals were not significantly different from sample members with more external LOC. The second question is to learn whether people with internal locos of control have better job performance compared with people with external locos of control. The third questions studies the role of job stressors as an interface between personal characteristics of locos control and job satisfaction. Finally, the last question is concerned with the effects of stressors as an interface between personal characteristics of locos control and job performance.

There is always a common sense that job satisfaction could increase employee performance. There are three different perspectives: the first one says satisfaction would lead to performance improvement while the other one assumes that the performance could increase employee's job satisfaction. Finally, the third theory insists that there is no relationship between job satisfaction and work performance and both of these issues are highly affected by employee characteristics and working environment. There have been weak supporting documents for the first two perspectives. In fact, there are many evidences to indicate that a satisfied employee does not necessarily yield relatively better performance. However, there are some strong evidences to show that work environment and employee performance could be a major of job satisfaction.

We normally expect a stable job performance in work environment with no stress and there is not much change on job performance. The job performance could be relatively low or high depending on what it was before and there is not much motivation for change on job performance. We may even expect a reduction in productivity when people work under no stress environment. When employee are under increasing pressure and stress there will be an increase on productivity but eventually the increase in stress will create nervous environment where the productivity is reduced (Gavin et al., 1985; Wood \& Wilson, 1988).

Chen et al. (2006) studied organization communication, job stress, organizational commitment, and job performance of accounting professionals for two countries of Taiwan and United States. They reported that there is not a significance difference in stress and communication levels between two countries but organizational commitment and performance levels were higher in the USA. They also reported that higher levels of organizational communication possibly could lead to higher levels of organizational commitment and job performance in both countries. The other interesting results of 
their studies indicated that stress levels were not related to either organizational communication or job performance.

\section{Proposed study}

In this paper, we present a study to examine the impact of job stress on the relationship between the LOC and accountants' job satisfaction. In our study, there were 304 senior and regular accountants who work for thirteen different regional municipality of city of Mashad located in east part of Iran. The study uses different well-known questionnaire method such as stress diagnostic survey, LOC, job satisfaction and employees' performance to perform the study. In our study, we have tried to divide all sample size into approximately 14 equal number of sections associated with different municipalities located in the city of Mashad. We have chosen the size of the population based on the following relationships,

$$
\begin{aligned}
& \mathrm{n}_{0}=\left(\frac{\mathrm{z}}{\mathrm{r}} \times \frac{\mathrm{S}}{\overline{\mathrm{Y}}_{\mathrm{N}}}\right)^{2}, \\
& \mathrm{n}=\frac{\mathrm{n}_{0}}{1+\frac{\mathrm{n}_{0}}{\mathrm{~N}}},
\end{aligned}
$$

where $r$ represents the error term, $N$ is the size of the population, $\overline{\mathrm{Y}}_{\mathrm{N}}$ is the average and $S$ is the standard deviation of the population, $Z$ is the percentile of $\left(1-\frac{\alpha}{2}\right)$ of the normal distribution and $n$ is the sample size. Using Eq. (1) and Eq. (2) yields a sample of 65 people for the study of this research. The study uses three different well-known questionnaire methods of stress diagnostic survey (SDS) (Ivancevich \& Matteson, 1983), locus of control (LOC) (Bernardi, 1997), job satisfaction and employees' performance (Frucot \& Shearon, 1991) to perform the study. In their study, we use the individual job stressor scale from the Ivancevich and Matteson (1983) stress diagnostic survey (SDS) to gather data concerning the various types of job stressors among a national sample of municipality accountants. The proposed study uses Likerd scale to gather the information and the quality of the gathered data are validated.

\subsection{Sample size characteristics}

The sample size of this study has different characteristics in terms of gender, education, marital status, etc. Sixty five percent of the sample size is women and 35 percent of them are man, 83 percent are married and over 80 percent have a minimum bachelor of accounting. Finally, 26 percent of the population is senior accountant, 74 percent is regular accountant, and the sampling is performed without replacement.

\section{Results}

Based on the results of this survey, the average stress score for senior and regular accountants were 126.12 and 132.23, respectively, which means that regular accountants have more stress than senior accountants do. In fact, over $80 \%$ of the senior accountants maintained a less than average stress while $72 \%$ of the regular accountants maintain average stress. Approximately, $71 \%$ of the senior accountants maintained an internal LOC, the rest of them had mixed LOC, and none of them had external LOC. Among regular accountants, $81 \%$ had internal LOC, $11 \%$ had almost external LOC and $8 \%$ experienced mixed LOC. In terms of job satisfaction, over $72 \%$ of senior accountants were completely satisfied of their jobs while only $56 \%$ of the regular accountants were either completely or relatively satisfied on their jobs. In terms of the job performance, $70 \%$ and $62 \%$ of the senior and regular accountants had outstanding job performance, respectively.

The preliminary results also indicated that over $65 \%$ of the survey people have relatively internal LOC, $8 \%$ of the survey people have external LOC, and no one had completely internal LOC. It was 
surprising to know that approximately $40 \%$ of the survey people were either completely or relatively unsatisfied about their job. On the contrary, $60 \%$ of the rest of the people were relatively satisfied. All managers had high evaluation rank on their supervisor or regular accountants with an average and standard deviation of 3.062 and 0.77, respectively. About stress and its components, the average, standard deviation and skew numbers were 130.63, 27.77 and -0.507 , respectively which indicate the level of stress is slightly more than average. In addition, the average numbers of stress components of role ambiguity and conflict, quantitative and qualitative overload and other people's responsibility were 16.62, 22.65, 22.95, 23.25, 23.14 and 17.43, respectively where the highest average belongs to quantitative overload and the lowest average belongs to role of ambiguity.

\subsection{Statistical analysis}

In order to make sure there is no correlation among six independent variables of this survey we performed Pearson test for each pair of our computations. We also executed Kolmogorov - Smirnof (Corder \& Foreman, 2009) to make sure that the data are normally distributed. The results had no indication on rejecting normality behavior of all six independent variables of role of ambiguity, role of conflict, quantitative and qualitative overloads, LOC, job satisfaction and job performance.

\subsubsection{The first hypothesis: Stress in not equally distributed among people with different LOC}

We consider a linear regression model where LOC is the independent variable and role of ambiguity, role of conflict, quantitative and qualitative overloads, LOC, job satisfaction and job performance are dependent variables. The results indicate that there is only meaningful relationship between the carrier development and LOC when the significant level is $5 \%$ and a relatively meaningful relationship between stress and LOC when the significant level is $10 \%$. In addition, there were no meaningful different between the average score numbers of all six independent variables based on MANOVA test.

\subsubsection{The second hypothesis: Job satisfaction in not equally distributed among people with different LOC}

Our regression test results indicated that there were no relationship between job satisfaction and other independent variables when the significant level is either $5 \%$ or even $10 \%$. The MANOVA test also yields the same results.

\subsubsection{The third hypothesis: Job performance in not equally distributed among people with different LOC}

Our regression test results indicated that there were no relationship between job performance and other independent variables when the significant level is either $5 \%$ or even $10 \%$. The MANOVA test also yields the same results.

\subsubsection{The fourth hypothesis: Stress plays an interface between LOC and job satisfaction}

On the contrary to the previous parts we used structural equation method to study the relationship. The results indicated that although LOC does not directly impact job satisfaction but it surely impact job satisfaction via stress when the significant level is $1 \%$. In other word, an increase on internal LOC will increase employees' stress and consequently this will eventually reduce job satisfaction. In addition, an increase on external LOC will also increase job satisfaction.

\subsubsection{The fifth hypothesis: Stress plays an interface between LOC and job performance}

In this part, we used the same structural equation method to study the relationship between LOC and other variables. The results indicated that LOC has no direct or indirect impact on job performance. However, as internal LOC increases, the job performance will also increase but when LOC comes with stress then we expect a reduction on job performance. 


\subsection{Summary}

Quantitative overload and shortage of budget normally lead us to expect more work from accountants. On the other hand, there are many tasks where there is no precise standard on duties and any inappropriate assignment of task could lead to improper task execution. Note that accounts encounter with heady duties during the end of fiscal season and once they are met with a high volume of tasks, which are not properly accomplished, they may make mistake. Therefore, it is recommended to setup a standard for all tasks before assigning them to people just to make sure that no one is overloaded with high volume of task execution.

Qualitative overload occurs when accountants are asked to some other responsibilities, which are not associated with their skills and knowledge. In such circumstances, we may expect a reduction on job satisfaction. One way to reduce such conflict of interest among accountants is to make all people familiar with rules and regulations and setup some short courses about what their organization expect them to do.

It is important to provide a crystal clear road map on currier plan for accountants so that they know how to get job promotion. A good a clear job promotion could help people to adjust accountants' expectations. Finally, it is important for any organization to learn more about employees' personal characteristics so that they could provide suitable packages for them.

\section{Conclusion}

In this paper, we have presented an empirical study to examine the impact stress on accounting job. We have studied the relationship between the LOC and different stress components such as role of ambiguity, role of conflict, quantitative and qualitative overloads, job satisfaction and job performance. The study selected a sample of 65 senior and regular accountants out of 304 people who worked for thirteen different regional municipalities of city of Mashad located in east part of Iran. The study used different well-known questionnaire methods such as stress diagnostic survey, LOC, job satisfaction and employees' performance to perform the study. The results indicate that the stress is on average level for the dominant locos of control factors and job satisfaction and employee performance are in relatively high level. The study also revealed that there are four important factors of role of ambiguity, quantitative overload, career development and handling other workers' responsibilities, which play important role on job satisfaction and managing career development has important impact on the performance of accountants.

\section{Acknowledgment}

This paper is supported by regional municipality of Mashad/Iran and the authors would like to thank them for providing the necessary documentation and data. The authors would like to thank the anonymous referees for their constructive comments on earlier version of this paper.

\section{References}

Bernardi, R.A. (1997). The relationships among locus of control, perceptions of stress, and performance. Journal of Applied Business Research, 13(4), 1-8.

Corder, G. W., \& Foreman, D. I. (2009). Nonparametric Statistics for Non-Statisticians: A Step-byStep Approach, Wiley, ISBN 9780470454619.

Chen, J.C., Silverthorne, C., \& Hung, J.Y. (2006). Organization communication, job stress, organizational commitment, and job performance of accounting professionals in Taiwan and America. Leadership \& Organization Development, 27(4), 242-249.

Frucot, V., \& Shearon, W. (1991). Budgetary participation, locus of control, and Mexican managerial performance and job satisfaction. The Accounting Review, 66(1), 80-90.

Gavin, T., Hammer, E., \& Taylor, L. (1985). Job satisfaction of internal auditors. Internal Auditing, 1, 64-73. 
Ivancevich, J.M., \& Matteson, M.T. (1983). Stress Diagnostic Survey, University of Houston, Houston, TX.

Lo, M. C., \& Ramayah, T. (2011). Mentoring and job satisfaction in Malaysian SMEs. Journal of Management Development, 30(11), 427-440.

Matteson, M.T., \& Ivancevich, J.M. (1987). Controlling Work Stress, Jossey-Bass, San Francisco, CA.

Patten, D.M. (2005). An analysis of the impact of locus-of-control on internal auditor job performance and satisfaction. Managerial Auditing Journal, 20(9), 1016-1029.

Sanders, J. C., Fulks, D. L., \& Knoblett, J. K. (1995). Stress and stress management in public accounting. The CPA Journal, 65, 46-49.

Wood, D.J., \& Wilson, J.A. (1988). Stress and coping strategies in internal auditing. Managerial Auditing Journal, 3(2), 8-16. 